\title{
Advances in Materials
}

\section{The Influence of Metal Surfaces on the Effect of Lubricants}

\author{
Jürgen Rigo ${ }^{1, ~ *, ~ P a v e l ~ K o v a c ̌ o ́ c y ~}{ }^{1}$, Joachim Schulz², Katja Vlasov² \\ ${ }^{1}$ Faculty of Materials Science and Technology, Slovak University of Technology in Bratislava, Trnava, Slovak Republic \\ ${ }^{2}$ Fuchs WISURA GmbH, Bremen, Germany
}

Email address:

juergen.rigo@stw.de (J. Rigo)

${ }^{*}$ Corresponding author

To cite this article:

Jürgen Rigo, Pavel Kovačócy, Joachim Schulz, Katja Vlasov. The Influence of Metal Surfaces on the Effect of Lubricants. Advances in Materials. Vol. 7, No. 3, 2018, pp. 58-66. doi: 10.11648/j.am.20180703.11

Received: June 12, 2018; Accepted: July 7, 2018; Published: August 13, 2018

\begin{abstract}
An important aspect of tribology and lubrication is the question of the relationships and the predictability of phenomena of the interaction of lubricants with metal surfaces. In recent years studies on interactions of antiwear additives and sulfur carriers have been presented. Significant differences in the interaction with different metal surfaces $(\mathrm{C}$ steel or stainless steel) could be observed. Recent studies have shown that a different, especially mechanical, pretreatment of metal surfaces (Csteel) can lead to very different results.
\end{abstract}

Keywords: Lubricants, Base Oil, Additives, Mechanical Testing, Tribological Test Rig, Brugger

\section{Introduction}

In the additive and lubricants sector there are divergent opinions on the interactions of lubricants, and the additives contained in them, with metal surfaces. On the one hand, the "old" reaction layer model and on the other hand the "younger" adsorption model. Both models can only be used with well-founded evidence.

Influencing the future properties of a component as a result of pretreatment is of central importance for its service life today. With the known models for the effectiveness of additives or their interactions with metal surfaces such statements are hardly possible. The situation becomes particularly precarious when attempts are made to incorporate the findings of the literature into simulation models that are currently in widespread use. With simple coefficients of friction, determined on tribological test machines, no simulation has yet yielded any useful results. Most of the work over the past six decades has been based on the formation of sliding-active reaction layers. There is definite evidence, even if it is often differently represented, for neither of the two models. For many phenomena in metal working (machining / forming) but also beyond, the adsorption model seems to offer more plausible explanations. In the current paper, the attempt is made to show that the metal surfaces of the tribological partners themselves can influence the performance of a lubricant or the additives contained therein, and that a change in the surface of the tribopartner can lead to a significant change in the friction and / or wear conditions.

For the lubricant formulator, the consequence is to adjust the composition of the lubricant to the surfaces of the tribological collective. It has long been known that lubricants (even from the same production batch) can lead to different results (performance-related). Since the composition of the lubricant within a batch as a rule does not change and the surface of the tool can also be regarded as quasi-constant, only the workpiece surface remains, and little is known of this.

However, it is generally accepted that the structure of a material, even in a coil, is subject to a certain fluctuation range. These variations should also affect the surface. An elucidation of a metal surface with regard to its chemical constitution is, however, a very difficult undertaking, not to mention online monitoring.

In addition to these aspects, there are the general problems of tribological testing. As mentioned above, one of the most important aspects of the lubricants, additives and tribological testing technology is the question of the inter-relationships and the predictability of phenomena which occur within the tribological systems. In addition to the complex tribological aspects of additive and metal chemistry, e.g., the mechanical- 
dynamic model testing of these properties and the interpretation of the results of this are of great importance.

Widely used test equipment is often used to test the performance of lubricants. Usually, these tests are carried out using standard test parameters (standardized tests according to DIN, ASTM and many other standards) which have no significant correlation with the parameters from practice. Often a wrong system analysis is to blame. Test results obtained from tribometer tests should be taken with caution and must be justified with field tests [1]. Furthermore, various apparatuses provide completely different results, e.g., through different engagement conditions, movements, lubrication conditions, temperatures, loads, etc. [2]

What result should one now trust? Does additive chemistry, for example, only appear in one device and then does it have to be correlated with practice?

What influence does the lubricant have on the test method [1]? How do we interpret the results of individual standards tests? Are there more similarities than differences? In some projects, it has been shown that with rigorous examinations according to common standards completely different rankings can occur [3].

For example, samples subjected to a welding force determination in the VKA have entirely different results to those which have been tested in the SRV test rig. This means that the appropriate candidate can only be chosen on the basis of the test method selected. But what is the right test method? For years there have been some tendencies where the best test is to show the positive properties of a lubricant or lubricant additive. Is this only due to the lubricant, or is
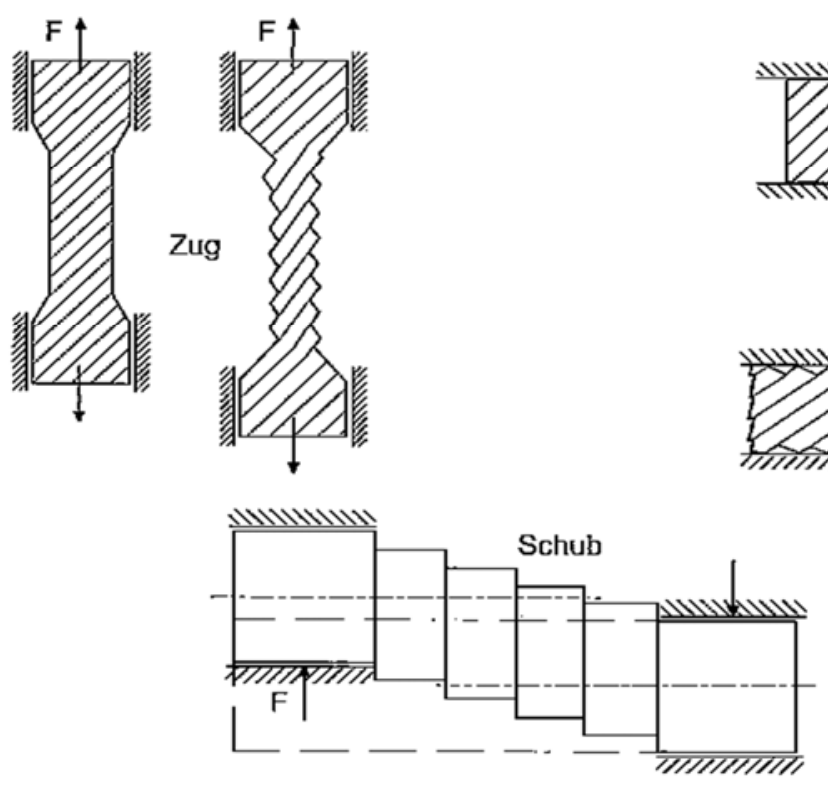

Figure 1. Sliding on the single crystal [6].

Of course, the above model ideas are also valid for polycrystalline materials, except that the presentation is no longer so easy. Also, the model pictured in figure 1 is valid not only for forming, but also for machining. Finally, cutting is also a forming process in which the blade is reshaped on the test procedure more significant [2]? Or even the preparation of the surface?

\section{Scope}

Metals are homogeneous only at first glance (macroscopically). On closer inspection, with corresponding microscopes, the crystalline structure is striking for both ferrous and non-ferrous metals. A crystalline structure precedes a fixed arrangement of the atoms making up the crystal. Depending on the metal, these crystals are more or less the same composition. The vast majority of metals are constructed according to the cubic or hexagonal crystal system. Within the cubic system it has to be distinguished between a space and surface-centered structure. In a real metal, mixed forms will always form between these types, so that there is hardly an ideal system.

For metalworking, defects in the lattice are of biggest importance. At the points of failure, micro-cracks can form, into which the surface-active (polar) additives of the metalworking fluids can penetrate. The effects of the grain boundaries for intercrystalline corrosion processes and pitting corrosion are described in detail [4]. In the latter case no additive but water attacks at the grain boundaries, of course. At the dislocations, the slip planes are formed, which are important for the deformation. Rehbinder [5] speaks of so-called "sliding parcels". Klocke [6] presents the very vivid model of a stack of cards consisting of the lattice layers and the intervening slip planes (figure 1).

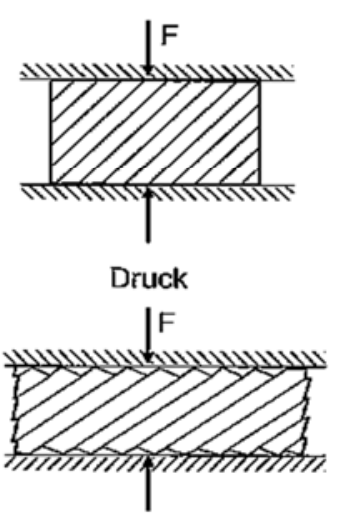

the cutting wedge until it breaks off. The emergence of new interfaces within a grain is an essential process in the forming of materials and in terms of the generation of nanoscale surface layer particularly worth mentioning. Real insights into and into the atomic structure are only possible 
with SIMS (Secondary Ion Mass Spectroscopy) and SNMS (Secondary Particle Mass Spectroscopy). For example, the surface of an untreated gear is described in [7] using SNMS. The existence of hydroxy- groups (-OH) is detected. These $\mathrm{OH}$ groups are bound to iron. Steel (not stainless steel) covers itself with a layer of hydroxides and oxides from a humidity of $40 \%$. Stratmann [8] gives the composition of an iron surface with about $25 \% \gamma-\mathrm{FeOOH}, 70 \% \alpha-\mathrm{FeOOH}$ and very small amounts of oxide. In a recent work [9] iron oxide $\left(\mathrm{Fe}_{3} \mathrm{O}_{4}\right)$ and iron hydroxide $\left(\mathrm{Fe}(\mathrm{OH})_{2}\right)$ are detected on an iron surface. Bhargava et al. [9] found a good agreement with the Pourbaix diagram for the iron-water system (figure 2). Iron oxide, iron (II) - and iron (III)- ions (occupied by hydroxide groups) thus exist side by side in the neutral $\mathrm{pH}$ - range.

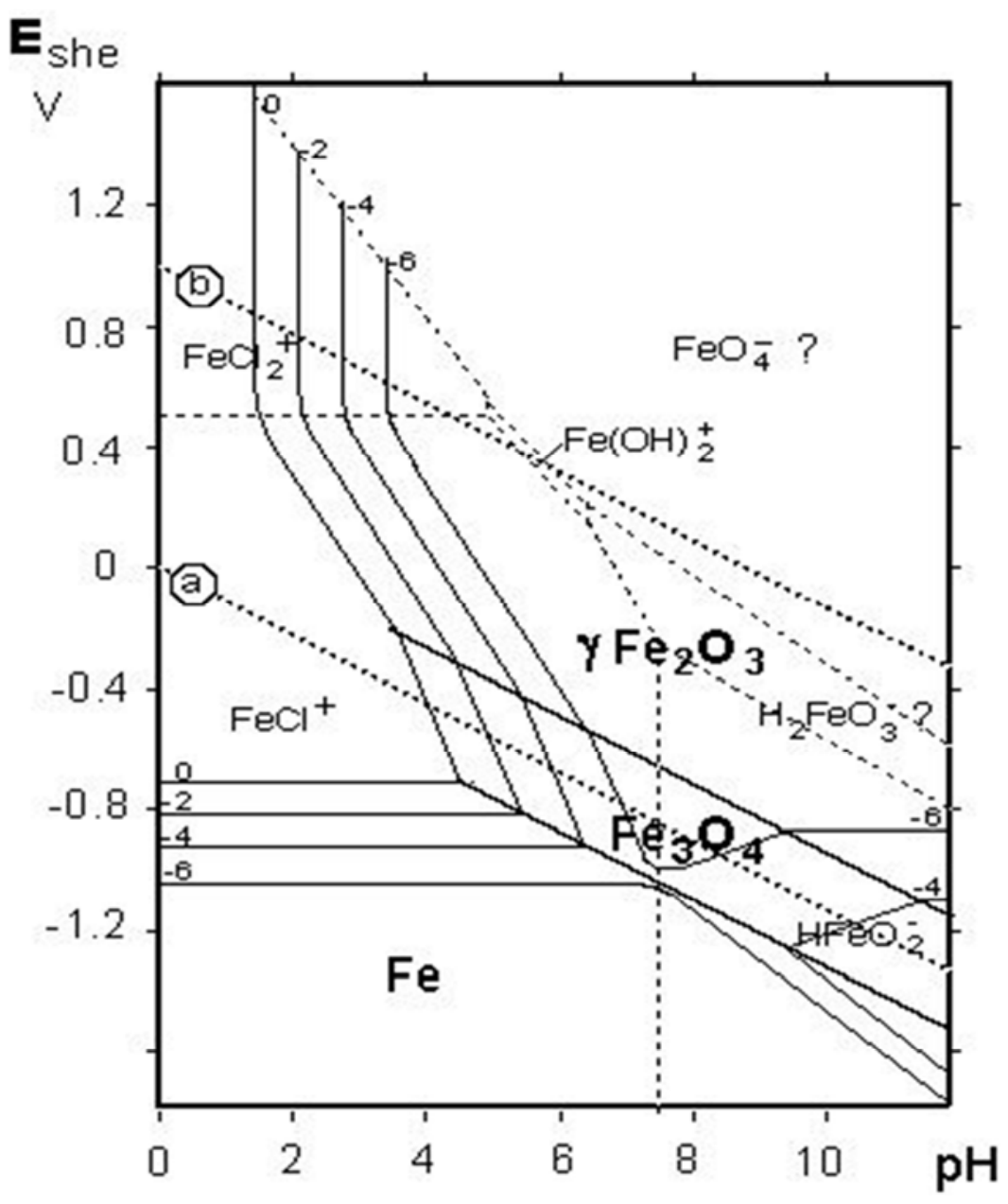

Figure 2. Pourbaix-diagram for the iron-water system [10].

It is generally known that stainless steels are covered by a chromium / nickel oxide layer, depending on the alloy in varying proportions. Aluminum is also known to be covered by a firmly adhering oxide skin. For normal grades of steel, it is assumed that there are oxides on the metal surface which, depending on the literature, are sometimes assumed to be surface-wide and sometimes island-shaped. When reporting possible reactions of lubricant additives, the illustrations are all pure iron surfaces. More often it has been reported of socalled "(re)active centers" around which the additives compete in adsorption. These "reactive centers" should be "mobile", i.e. they are not stationary on a certain iron surface. Unfortunately, the literature on the last point is very nebulous. Hotten writes in the discussion on the Forbes essay [11]: "Iron is a chameleon - it changes is skin with the surroundings."

That with the first interaction of an additive with the metal surface, the electronic situation of the metal surface drastically changes, at least in the surroundings of this first interaction. Thus, subsequent additives will find other conditions for interaction than the first additive.

If, as in the case of iron, ions are present in different oxidation states (Fe (II), Fe (III) and possibly also Fe (0) atoms), it is quite conceivable that a permanent change of the oxidation states can take place with each other. Finally, this requires only the displacement of single electrons.

This could easily explain the phenomenon of "mobile reactive centers".

Let's return to the crystalline structure of the metals in this context. As described above, the individual crystals and thus the unit cells can be oriented differently. This certainly influences the energetic situation on the metal surface. Where and how tightly bound a hydroxide group is, which point on the surface is covered with oxide or not and not least how 
fast and in which direction electron movements are possible, depends on the internal structuring of the metal. The orientation of the crystals ultimately determines the interaction of the metal surface with the lubricant additives. In many processing methods, fresh surfaces are produced. This is generally the case in machining, but new surfaces also result from many forming processes.

If these newly formed surfaces are not immediately covered by additives, welding (adhesion) of workpiece material with tool material occurs.

This effect occurs with stainless steels, aluminum and titanium, so materials, which carry a pure oxide skin, much more strongly in appearance than with steel or copper. Trivial this behavior is called "sticking". The freshly exposed metal has the oxidation state $(0)$ and is eager to enter into a new chemical bond or at least to experience some saturation of its surface by adsorption. The oxidation state (0) is an "unstable" state for metals. Stabilization is nothing other than changing the electronic situation at the corresponding metal atom. Theoretically, such stabilization could also be done by an internal shift of electrons. I.e. electrons must be released from the atom with oxidation state $(0)$ and taken up by another atom with an oxidation state $>(0)$. In the case of iron, as an example, the oxidation states (II) and (III) are present as described above. Atoms with the oxidation state (III) would convert by electron uptake into the step (II), which is stable. If, as in the case of stainless steels, aluminum and titanium, there are no atoms in the same workpiece that could pick up electrons, the internal electron transfer is hardly possible. As a result, the change in the electronic situation can only occur through reaction with external "reactants" (additives, tool material).

A secure avoidance of adhesions is only guaranteed if the additives can quickly cover the new surface and are bound relatively firmly adsorptive.

Thus, additives can only interact with oxides, hydroxide groups or metal ions. In general, the additives may be subdivided according to their structure into two major groups, ionic (e.g., acidic phosphoric acid esters, PEP additives) and nonionic species (e.g. chloroparaffins, polysulfides). The ionic additives will certainly preferably correspond to the metal ions. The nonionic additives should be able to come to terms with both the oxides and the hydroxide groups. In purely phenomenological terms, the above thesis agrees with observations from practice. For stainless steel processing, PEP additives or acidic phosphoric acid esters are of secondary importance. Chloro-paraffins and sulfur compounds are used successfully here.

In steel, PEP additives have proven themselves in combination with sulfur compounds. To clarify the behavior of additives on / with metal surfaces, a number of additives or combinations of these were investigated by means of the Brugger test according to DIN 51347 [12-14].

It is, however, possible to simulate different states of metal surfaces in the laboratory. Thus, it could be observed that the same lubricant in the Brugger test in accordance with DIN 51347 may produce different results than in the same mode with the XCT machine (XCT $=$ cross-cylinder-tester $)$. Both tribological test machines work according to the same principle. The surface pressures can also be adjusted identically. The difference in the sample preparation between the two methods consists solely of the fact that the friction roller of the Brugger is prepared with a grinding stone and the friction roller of the XCT with abrasive paper of the same grain size. The same phenomenon can also be observed on one of the test machines (Brugger or XCT), reproducibly when both grinding methods are used.

A first guess suggested fine-grained abrasion which, if left on the friction roller due to improper cleaning, could act like solid lubricant. This could be disproved since different cleaning methods of the friction roller after the grinding process did not lead to any significant change in the results obtained. Also, the presumption that it would be due to a special additive (polysulfide) could not be confirmed.

The described phenomenon for sulfurized esters, but not for a polysulfide, was observed during a preliminary study on a master thesis [15]. Hoffmann et al. [16] stated the observed phenomenon can be attributed to different roughness's of the ground friction roller surface. This is to be contradicted in the further remarks.

\section{Experimental Section}

\subsection{General}

An XCT device (Steinbeis Transferzentrum at Mannheim University of Applied Sciences) and a Brugger device (Fuchs Wisura $\mathrm{GmbH}$ ) were used for the tests. As a friction roller, the standard version (hardened to $>60 \mathrm{HRC}$, material X210CrW12 (1.2436)) was used. The test specimens were made of 100Cr6 (1.3505), also hardened to $60 \mathrm{HRC}$.

The friction rollers (all from a production batch) were sanded with the standard SiC grindstone, grade P 120 and abrasive papers of grades $60,120,320$ and 800 . The surface topography of the pretreated friction roller was measured with a white light interferometer. It functions as a non-contact surveyor of topographies of workpieces with a large spatial depth resolution. Here, even rough surfaces can be measured up to the nanometers. Table 1 shows the determined roughness's.

Table 1. Determined roughness of the surfaces.

\begin{tabular}{llll}
\hline \multirow{2}{*}{ Grinding Procedure } & Average Surface Roughness & 3D-Surface-Characteristics in $\boldsymbol{\mu m}$ \\
\cline { 2 - 4 } & Rz in $\boldsymbol{\mu m}$ & Sa & Sq \\
\hline Only abrasive block (Standard) & 3.1 & 0.4 & 0.6 \\
Abrasive block +800 abrasive paper & 2.0 & 0.3 & 0.4 \\
Abrasive block +320 abrasive paper & 2.4 & 0.5 & 0.6 \\
Abrasive block +120 abrasive paper & 5.2 & 1.0 & 1.5 \\
Abrasive block +60 abrasive paper & 9.0 & 0.7 & 1.0 \\
\hline
\end{tabular}




\subsection{Cross-Cylinder-Tester (XCT)}

The cross-cylinder tester (XCT) (figure 3 ) is a test device developed at the Tribology Competence Centre that combines the two well-known testing methods according to Brugger and Reichert. By a simple conversion, both variants are carried out on the same test device. The Brugger-test, performed with the XCT, is a standardized method (DIN51347) using the friction conditions in the contact zone between friction ring $(\varnothing=25 \mathrm{~mm}$, material 1.2436, hardness $60 \mathrm{HRC}$, grinded) and a test cylinder $(\varnothing=18 \mathrm{~mm}, 100 \mathrm{Cr} 6$ (1.3505), hardness $62 \mathrm{HRC}$, polished), whose axes are offset by $90^{\circ}$ to each other. It is firmly clamped in a rotatable holder and is pressed from the latter by a weight against the rotating test ring. The sliding velocity is $1.2 \mathrm{~m}$ per s. Now the test ring is poured over the lubricant to be examined. The test cylinder is pressed against the test ring at $400 \mathrm{~N}$. The test duration is 30 seconds. Depending on the lubricant property, a different sized wear scar is produced on the stationary test cylinder from the rotating test ring. The wear surface has the shape of an ellipse (Figure 3, right) and the principal axes of the ellipse are measured. From this, the projected area of the wear surface is calculated. The quotient of the pressing force and projected wear surface is specified as a load capacity of the lubricant according to Brugger $\left(\mathrm{N}\right.$ per $\left.\mathrm{mm}^{2}\right)$.
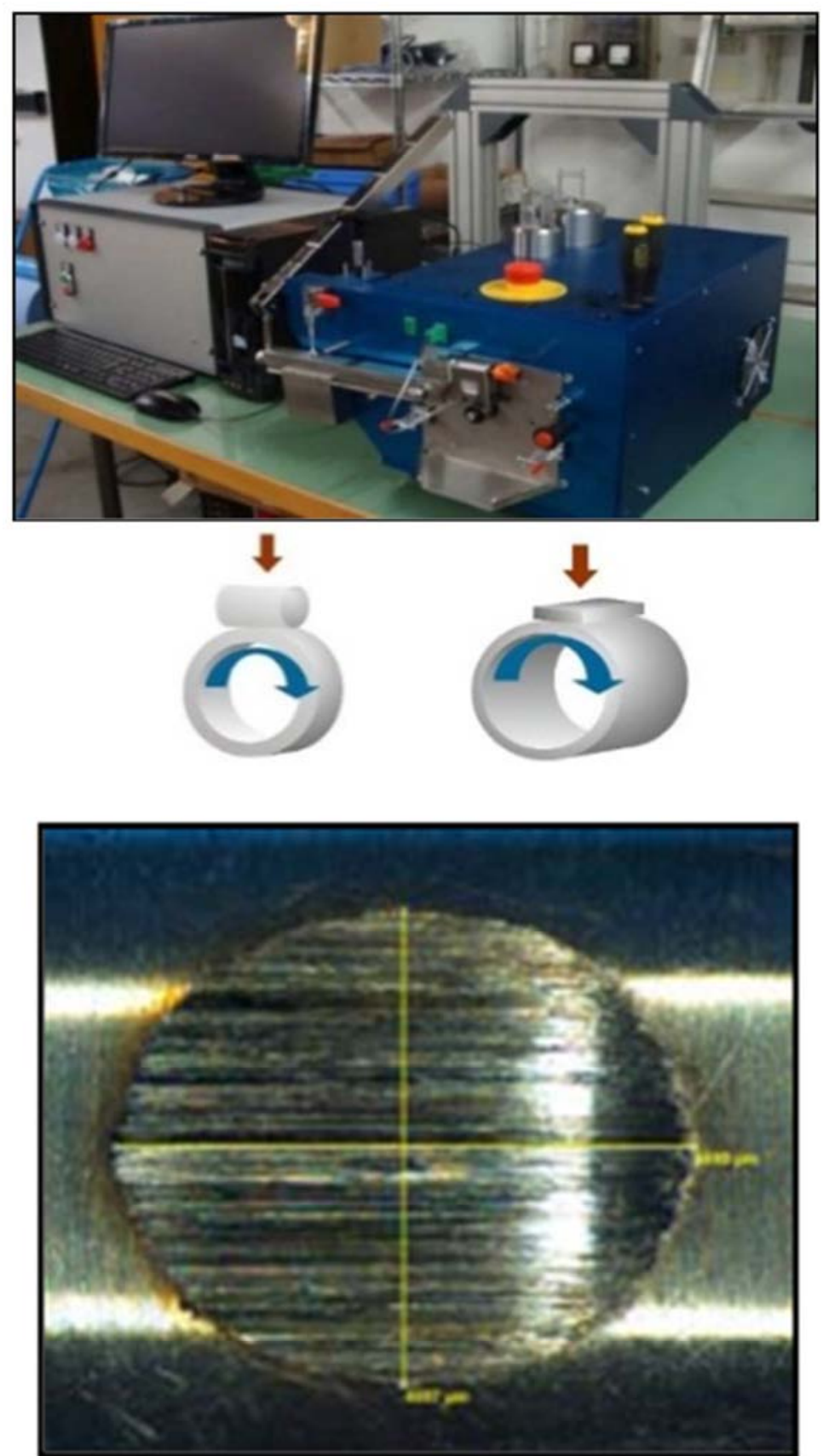

Figure 3. XCT, common test specimen and typical wear mark. 


\section{Used lubricants}

Table 2. Investigated substances or mixtures.

\begin{tabular}{|c|c|}
\hline Name & Chemical Consistence \\
\hline Matrix 1 & $100 \%$ base oil \\
\hline Matrix 2 & $(\mathrm{X}+\mathrm{A}+\mathrm{B}) \%$ base oil / $(\mathrm{C}) \%$ additive type $\mathrm{M} 2$ \\
\hline Matrix 3 & $(\mathrm{X}+\mathrm{B}+\mathrm{C}) /(\mathrm{A}) \%$ additive type $\mathrm{M} 3$ \\
\hline Matrix 4a / 4b & $\begin{array}{l}(\mathrm{X}+\mathrm{A}+\mathrm{C}) \% \text { base oil } /(\mathrm{B}) \% \text { additive type } \mathrm{M} 1 \mathrm{a} \\
(\mathrm{X}+\mathrm{A}+\mathrm{C}) \% \text { base oil } 1 /(\mathrm{B}) \% \text { additive type } \mathrm{M} 1 \mathrm{~b}\end{array}$ \\
\hline Matrix 5 & (X+B)\% base oil / (A)\% additive type M3 / (C)\% additive type M2 \\
\hline Matrix $6 \mathrm{a} / 6 \mathrm{~b}$ & $\begin{array}{l}(\mathrm{X}+\mathrm{A}) \% \text { base oil } /(\mathrm{B}) \% \text { additive type } \mathrm{M} 1 \mathrm{a} /(\mathrm{C}) \% \text { additive type } \mathrm{M} 2 \\
(\mathrm{X}+\mathrm{A}) \% \text { base oil / (B)\% additive type M1b / (C)\% additive type } \mathrm{M} 2\end{array}$ \\
\hline Matrix 7a / 7b & $\begin{array}{l}(\mathrm{X}+\mathrm{C}) \% \text { base oil / (A)\% additive type M3 / (B)\% additive type M1a } \\
(\mathrm{X}+\mathrm{C}) \% \text { base oil / (A)\% additive type M3 / (B)\% additive type M1b }\end{array}$ \\
\hline Matrix $8 \mathrm{a} / 8 \mathrm{~b}$ & $\begin{array}{l}\text { (X)\% base oil / (A)\% additive type M3 / (B)\% additive type M1a / (C)\% additive type M2 } \\
\text { (X)\% base oil / (A)\% additive type M3 / (B)\% additive type M1b / (C)\% additive type M2 }\end{array}$ \\
\hline
\end{tabular}

\section{Results}

\subsection{XCT Results}

Table 3 and figure 4 show the results of the experiments on the XCT-device. It is striking at first glance that Matrices 1, 2, 3, 4 and 6 shows no influence of the grinding process, i.e. the prepared surface, on the result. Matrices 5, 7 and 8 show a strong dependence on the surface pretreatment. Matrices 3, 5, 7 and 8 contain polysulfide, i.e. an M3-type additive, in the same concentration. Nevertheless, the determined values of matrix 3 remain independent of the grinding process. Thus, it is to be excluded that a special effect of this additive plays a role. An interpretation of the values can be found in the following chapter.

Table 3. Testing results according to Brugger. Tests performed with the XCT.

\begin{tabular}{|c|c|c|c|c|c|}
\hline \multirow[b]{2}{*}{ Matrix } & \multicolumn{5}{|c|}{ Brugger-Value $\left[\mathrm{N} / \mathrm{mm}^{2}\right]$} \\
\hline & Abrasive block & $\begin{array}{l}\text { Abrasive block }+60 \\
\text { abrasive paper }\end{array}$ & $\begin{array}{l}\text { Abrasive block }+120 \\
\text { abrasive paper }\end{array}$ & $\begin{array}{l}\text { Abrasive block }+320 \\
\text { abrasive paper }\end{array}$ & $\begin{array}{l}\text { Abrasive block }+800 \\
\text { abrasive paper }\end{array}$ \\
\hline 1 & 19.3 & 20.6 & 21.3 & 20.7 & 19.7 \\
\hline 2 & 41.0 & 43.8 & 41.4 & 43.9 & 34.3 \\
\hline 3 & 114 & 115.8 & 117.5 & 112.9 & 113 \\
\hline $4 a$ & 19.4 & 21.3 & 21.1 & 21 & 18.9 \\
\hline 5 & 105.7 & 168.7 & 187.3 & 126.5 & 195 \\
\hline $6 a$ & 40.2 & 38.6 & 41 & 43.5 & 39.7 \\
\hline $7 a$ & 142.5 & 312 & 225 & 174.7 & 111.7 \\
\hline $8 \mathrm{a}$ & 154.8 & 411 & 419 & 425 & 366 \\
\hline
\end{tabular}

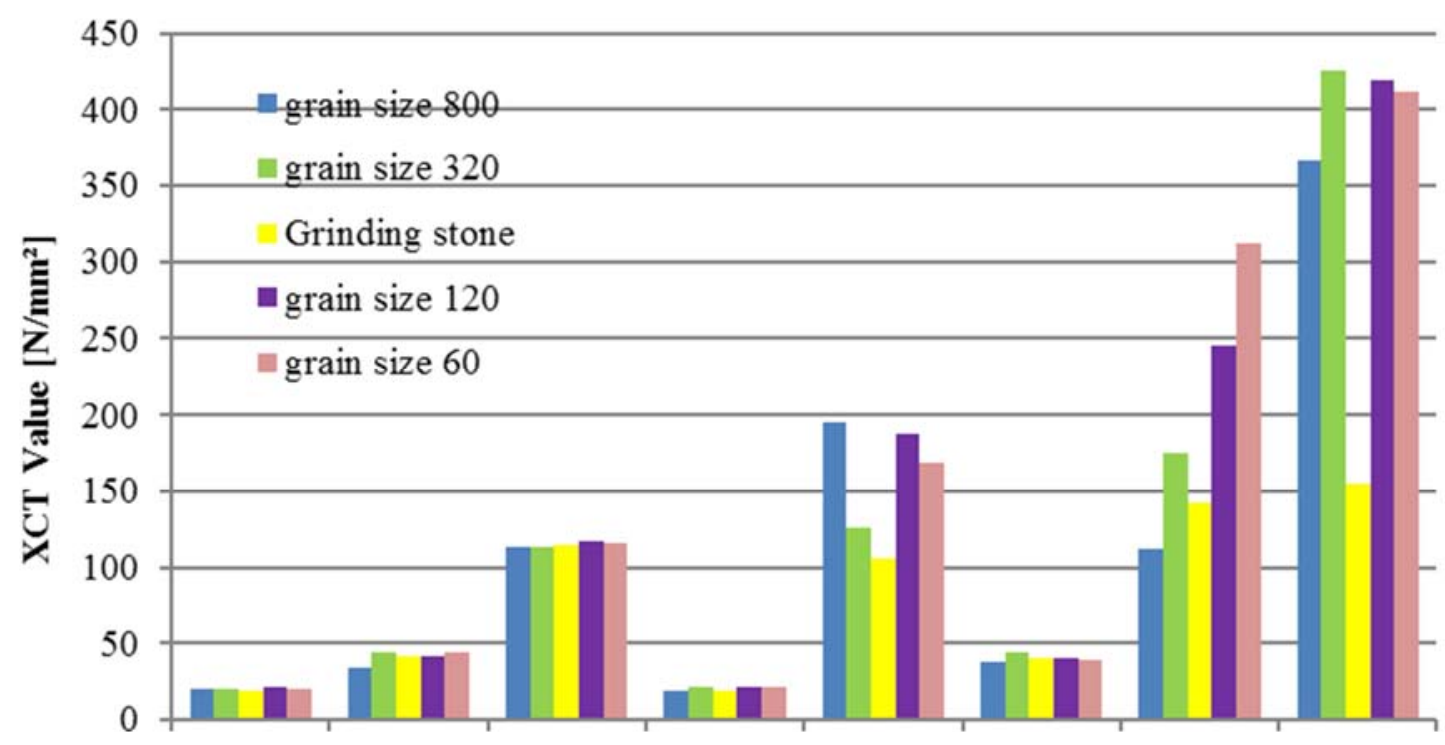

Matrix 1 Matrix 2 Matrix 3 Matrix 4 Matrix 5 Matrix 6 Matrix 7 Matrix 8

\section{Test Sample}

Figure 4. Testing results according to Brugger with different grinding procedures; performed with XCT. 
Two different test specimen batches from 100Cr6 were used in the tests on the Brugger device. The standard quality had a hardness of $62.5 \mathrm{HRC}$, the second batch of $61.9 \mathrm{HRC}$. In addition to the SiC grindstone, only abrasive paper with grain size 120 was used in these tests.

\subsection{Brugger Results}

The results are listed in Table 4.

Table 4. Testing Results according to Brugger. Tests performed with the original Brugger device.

\begin{tabular}{|c|c|c|c|c|}
\hline \multirow{3}{*}{ Matrix } & \multicolumn{4}{|l|}{ Brugger - Value $\left[\mathrm{N} / \mathrm{mm}^{2}\right]$} \\
\hline & \multicolumn{2}{|c|}{ Test specimen hardness 62.5 HRC } & \multicolumn{2}{|c|}{ Test specimen hardness 61.9 HRC } \\
\hline & grinded with abrasive block & $\begin{array}{l}\text { grinded with abrasive block }+ \\
120 \text { abrasive paper }\end{array}$ & grinded with abrasive block & $\begin{array}{l}\text { grinded with abrasive block }+ \\
120 \text { abrasive paper }\end{array}$ \\
\hline 1 & 19.3 & 19.3 & 21.3 & 21.4 \\
\hline 2 & 52.0 & 46.5 & 51.7 & 50.2 \\
\hline 3 & 61.2 & 60.9 & 69.0 & 65.7 \\
\hline $4 a$ & 37.7 & 22.3 & 28.7 & 22.9 \\
\hline $4 b$ & 31.4 & 25.5 & 24.3 & 24.3 \\
\hline 5 & 146.3 & 199.8 & 121.9 & 167.7 \\
\hline $6 a$ & 63.9 & 55.5 & 51.2 & 53.3 \\
\hline $6 b$ & 93.3 & 61.2 & 60.3 & 53.9 \\
\hline $7 \mathrm{a}$ & 97.1 & 230 & 73.2 & 141.5 \\
\hline $7 b$ & 76.4 & 93.8 & 80.6 & 109 \\
\hline $8 a$ & 189 & 270 & 171.6 & 200 \\
\hline $8 b$ & 187.8 & 303 & 199.8 & 200 \\
\hline
\end{tabular}

\section{Interpretation of Results}

First, the results of the investigations are to be compared with the XCT and the Brugger apparatus (Table 5). When interpreting the results, however, always consider the fact that two surfaces, the friction roller and the test body, influence the lubricant mixture.

Table 5. Comparison of the results.

\begin{tabular}{|c|c|c|c|c|c|c|}
\hline \multirow{3}{*}{ Matrix } & \multirow{2}{*}{\multicolumn{2}{|c|}{ XCT - Value [N/mm²] }} & \multicolumn{4}{|c|}{ Brugger - Value [N/mm²] } \\
\hline & & & \multicolumn{2}{|c|}{ Test specimen hardness 62.5 HRC } & \multicolumn{2}{|c|}{ Test specimen hardness 61.9 HRC } \\
\hline & $\begin{array}{l}\text { grinded with } \\
\text { abrasive block }\end{array}$ & $\begin{array}{l}\text { grinded with abrasive } \\
\text { block }+120 \text { abrasive paper }\end{array}$ & $\begin{array}{l}\text { grinded with } \\
\text { abrasive block }\end{array}$ & $\begin{array}{l}\text { grinded with abrasive } \\
\text { block }+120 \text { abrasive paper }\end{array}$ & $\begin{array}{l}\text { grinded with } \\
\text { abrasive block }\end{array}$ & $\begin{array}{l}\text { grinded with abrasive block } \\
+120 \text { abrasive paper }\end{array}$ \\
\hline 1 & 19.3 & 21.3 & 19.3 & 19.3 & 21.3 & 21.4 \\
\hline 2 & 41.0 & 41.4 & 52.0 & 46.5 & 51.7 & 50.2 \\
\hline 3 & 114 & 117.5 & 61.2 & 60.9 & 69.0 & 65.7 \\
\hline $4 a$ & 19.4 & 21.1 & 37.7 & 22.3 & 28.7 & 22.9 \\
\hline $6 a$ & 40.2 & 41 & 63.9 & 55.5 & 51.2 & 53.3 \\
\hline $7 a$ & 142.5 & 225 & 97.1 & 230 & 73.2 & 141.5 \\
\hline $8 \mathrm{a}$ & 154.8 & 419 & 189 & 270 & 171.6 & 200 \\
\hline
\end{tabular}

It can be seen clearly that the values do not correspond in part, but the tendencies and the effect of the grinding process clearly stand out in all cases. Also, the surface of the test specimens appears to have a not insignificant influence. In general, the Brugger lubricant test has a permissible deviation of \pm 10 .

In the case of an interpretation of the results, small fluctuations of the results should not be over evaluated.

Influence of roughness

The assumption that only the change in the roughness friction roller is responsible for changing the results leads directly into a dead end. The mixtures in matrices 1, 2, 3 show no real effect, independent of the test specimen and of the grinding process (Table $3 / 4 / 5$ and figure 4 ). In the case of mixture matrix 6 , there is no effect at the XCT, and a negative influence of grinding with paper can be determined on the
Brugger device (depending on the specimen and the type of the $\mathrm{M} 1$ additive). If the change in roughness were decisive, the results would have to show a uniform trend, which can certainly be ruled out here. This is not to say that the roughness has no influence, but only that it is not decisive.

Influence of the metal surface

The metal surface of carbon steels, which are both the friction rollers used and the test specimens, consists chemically of iron oxides and iron hydroxides as described in [12] and literature cited therein. The additives in the tested mixtures can only interact with these two groups on the metal surfaces or with themselves. Due to the different grinding processes, the surface is obviously changed, and the interaction of the additives is determined. Also, the surfaces of the test specimens used (the two on the Brugger device, also viewed from one another, and the test specimen on the 
XCT) appear to be chemically different. The results cannot be interpreted differently since the tested mixtures were the same batches. Generally speaking, it appears that the surface of the XCT specimen is significantly more oxidic than the test specimens used at Brugger.

The test specimen with a hardness of 62.5 HRC appears again to be more oxidic than the test specimen with 61.9 HRC. The working hypothesis is that the proportion of oxidic or hydroxydic groups on the two metal surfaces considered determines the possibilities of docking (adsorption) of the additives. First, it is very exciting that the observed effects are very low when mixtures with only one type of additive are tested in the base oil or the base oil alone. This is also the case when, as in the case of matrix 3, an active sulfur compound is present in a very high concentration (20-30\%). The significantly higher value on the XCT can be explained by the higher oxidic surface. Likewise, this is the case for the lower values of matrices 2 and 4 on the XCT.

Matrix 4 is to be discussed here, even if the observed effects are very small. On the XCT test specimen, matrix $4 \mathrm{a}$ shows no effect, compared to matrix 1 , i.e. no or very few surface areas are occupied. If the proportion of hydroxide groups increases significantly, more docking points for hydrogen bridges exist and the Brugger value increases. Grinding with abrasive paper reduces the amount of hydroxide groups and thus reduces the possibilities for mechanism M1, which is reflected in the decrease in the values determined. The interaction of the M1 type additive a appears to be somewhat stronger than that of the M1 type additive $\mathrm{b}$. Possibly the M1 type additive $\mathrm{b}$, due to another stereochemistry, can also interact with oxidic groups.

Significantly greater are the effects when combining additives or when changing stereochemistry (matrices 5, 6a/ 6b, 7a / 7b, 8a / 8b). In matrix 5, M2- and M3-type additives are present which can synergistically complement each other when both additives find sufficient docking sites. The M3 type obviously has a greater impact on the results. Matrix 6a / $6 \mathrm{~b}$ interacts mainly with the hydroxide groups via hydrogen bond and ionic bonds. If these hydroxides are not present or are only present in small numbers or are reduced, the measured values decrease. However, the effects are low. Matrix $7 \mathrm{a} / 7 \mathrm{~b}$ is again dominated by the number of oxidic groups. M1 and M3 complement each other. The M1 type additive $\mathrm{b}$ also obviously interacts with mechanism M3 and thereby hinders the M3 type additive. As a result, the values of the sample $7 \mathrm{~b}$ decrease as compared to $7 \mathrm{a}$. Matrix 8 , containing the complete mixture of all three additive types, yields the highest values. Here, too, the influence of the oxidic groups is unmistakable. With Matrix 7a the influence of the surfaces will be demonstrated once more. After grinding with abrasive paper, the friction rollers are obviously more oxidic than after grinding with the stone. The oxidic character of the test specimens decreases in the series of test specimens (used for the XCT measurements), test specimens with $65.5 \mathrm{HRC}$ and test specimens with 61.9 HRC. In the following Table 6 the oxidic character is represented by the number of "+", i.e. the more "+", the greater the proportion of oxidic groups on the surface.

Table 6. Influence of the number of oxidic groups on the surfaces on the level of the determined values at the XCT and Brugger.

\begin{tabular}{|c|c|c|c|c|}
\hline \multicolumn{2}{|l|}{ Test Specimen } & \multicolumn{2}{|l|}{ Friction Roller } & \multirow{2}{*}{ XCT- resp. Brugger-Value $\left[\mathrm{N} / \mathrm{mm}^{2}\right]$} \\
\hline Description & Number of oxidic groups & Machining & Number of oxidic groups & \\
\hline Used with XCT & +++++ & grinded with abrasive block & +++ & 142.5 \\
\hline Used with XCT & +++++ & grinded with 120 abrasive paper & ++++ & 225 \\
\hline $62.5 \mathrm{HRC}$ & +++ & grinded with abrasive block & +++ & 97.1 \\
\hline $62.5 \mathrm{HRC}$ & +++ & grinded with 120 abrasive paper & ++++ & 230 \\
\hline $61.9 \mathrm{HRC}$ & ++ & grinded with abrasive block & +++ & 73.2 \\
\hline $61.9 \mathrm{HRC}$ & ++ & grinded with 120 abrasive paper & ++++ & 141.5 \\
\hline
\end{tabular}

\section{Conclusion}

The results presented are consistent in themselves and very easy to explain with the model according to Schulz. An explanation according to the reaction layer model is not possible. The statements are hypothetical and would be supported by an elaborate analysis of metal surfaces. However, the evidence found is very important and is also consistent with previously found results. It could be shown that the different chemical structure of the metal surfaces under investigation interferes massively with the interaction of the additives or their mixtures. Each discrete mixture yields clearly differentiated values depending on the character of the surfaces.

The proportion of oxidic groups was found to be dominant. By grinding with abrasive paper, regardless of the grain size, the metal surface of the friction rollers becomes more oxidic, with differences in the quantity of the effects.
The roughness plays a rather subordinate role.

\section{Nomenclature}

DIN: Deutsche Institut für Normung

ASTM: American Society for Testing and Materials

GfT: Gesellschaft für Tribologie

XCT: Cross-Cylinder-Tester

\section{References}

[1] M. Grebe, Tribometry - an underestimated science, in: Annual GfT-Meeting 2016, Göttingen (in German).

[2] Rigo, J., Kovačócy, P.: “Comparative analysis of standardized test methods on common tribological test rigs" International Journal of Mechanical Engineering and Automation Volume 4, Number 4, 2017, pp. 130-137, October 25th, 2017. 
[3] Rigo, J., Kovačócy, P. "Tribological test rig results using standardized and diversified test methods". 21st International Colloquium Tribology - Industrial and Automotive Lubrication, Esslingen. January 9 - 11 th 2018.

[4] Kaesche, H.: Die Korrosion der Metalle, 3. Auflage, Springer Berlin, Heidelberg, New York, London, Paris, Tokyo, Hong Kong, Barcelona 1990.

[5] Lichtman, W. I., Rehbinder, P. A., Karpenko, G. W.: Der Einfluss grenzflächenaktiver Stoffe auf die Deformation von Metallen, Akademie-Verlag, Berlin 1964.

[6] Klocke, F.; König, W.: Fertigungsverfahren Umformen, 5. Auflage, Springer Berlin Heidelberg New York 2006. (in German).

[7] FVA Forschungsvorhaben 289, Abschlussbericht, Heft 595, 2000.

[8] Stratmann, M., Hoffmann, K., Müller, J.: Die Bedeutung von Rostschichten für den Ablauf von Korrosionsreaktionen bei niedrig legierten Stählen, Werkstoffe und Korrosion 42, 1991.

[9] Bhargava, G., Gouzman, I., Chun, C. M., Ramanarayanan, T. A., Bernasek, S. L.: Characterisation of the "native" surface thin film on pure polycrystalline iron: a high resolution XPS and TEM study, Applied Surface Science 253 (2007) 43224329.
[10] www.geocities.com/neveyaakov/electro_science/pourbaix.html)

[11] Forbes, E. S., Reid, A. J. D.: Liquid phase adsorption / reaction studies of organo-sulfur compounds and their load carrying mechanism, ASLE Trans. (16) 1, S. 50-60 1973.

[12] Schulz, J.; Holweger, W.: Wechselwirkung von Additiven mit Metalloberflächen; expert Verlag - 2010; ISBN: 978-3-81692921-5.

[13] J. Schulz, P. Feinle, A. Hirdt, J. Rigo, G. Pfeiffer, C. Seyfert. Possibilities of the development of forming products based on test machine values, in: Annual GfT- Meeting 2011, Göttingen. (in German).

[14] Schulz, J., Decker, B., Rehbein, W., Feinle, P., Rigo, J.: Matrix-Effekte -Einfluss der Schmierstoffmatrix auf die Wechselwirkung von Additiven mit Metalloberflächen; Tribologie und Schmierungstechnik 2 / 2013.

[15] Hohenäcker, D. 2016. Wechselwirkungen von Schwefelträgern mit Metalloberflächen unter der Berücksichtigung von Matrixeffekten. Universität Bremen, Germany.

[16] Hoffmann, T.; Drechsler, A., Lehmann, D.: Einflüsse der Oberflächenrauheit auf den Verschleißschutz von Schmierstoffen; Tribologie und Schmierungstechnik 4 / 2016. 